\title{
Leachability of metals from sludge-based artificial lightweight aggregate
}

\author{
Fang-Chih Chang ${ }^{a}$, Shang-Lien Lo ${ }^{\mathrm{a}, *}$, Ming-Yu Lee ${ }^{\mathrm{b}}$, Chun-Han Ko ${ }^{\mathrm{a}}$, Jyh-Dong Lin ${ }^{\mathrm{b}}$, \\ Su-Chen Huang ${ }^{\mathrm{c}}$, Chu-Fang Wang ${ }^{\mathrm{c}}$ \\ ${ }^{a}$ Research Center for Environmental Pollution Prevention and Control Technology, Graduate Institute of Environmental Engineering, \\ National Taiwan University, 71 Chou-Shan Road, Taipei 106, Taiwan, ROC \\ ${ }^{\mathrm{b}}$ Department of Civil Engineering, National Central University, 300 Jhongda Road, Jhongli 320, Taiwan, ROC \\ ${ }^{c}$ Department of Atomic Science, National Tsing Hua University, 101, Sec. 2, Kuang Fu Road, Hsinchu 300, Taiwan, ROC
}

Received 18 July 2006; received in revised form 29 November 2006; accepted 30 November 2006

Available online 10 December 2006

\begin{abstract}
Metal sludge from industrial wastewater treatment plants was mixed with mining residues to be recycled into lightweight aggregate (LWA) through sintering at different temperatures. The physical properties of the LWA thus obtained were examined by scanning electron microscopy analyzer (SEM) coupled with an energy dispersive X-ray analyzer (EDX). The sequential extraction method combined with inductively coupled plasma atomic emission spectrometry (ICP-AES) was employed to determine the concentration and distribution of hazardous toxic elements in the metal sludge-based artificial LWA. The results show that the leaching concentrations of $\mathrm{Cd}, \mathrm{Cr}, \mathrm{Cu}$, and $\mathrm{Pb}$ present in the non-sintered raw aggregate pellets reached 7.4,68.0,96.0, and $61.4 \mathrm{mg} / \mathrm{l}$, respectively, far exceeding the regulatory threshold. Sintering at $1150{ }^{\circ} \mathrm{C}$ for $15 \mathrm{~min}$ results in stronger chemical bonds being formed between the elements. Hence, after the first three steps of sequential extraction, the concentrations of $\mathrm{Cr}$, $\mathrm{Cu}$, and $\mathrm{Pb}$ reached $2.69,1.50$, and $1.88 \mathrm{mg} / \mathrm{l}$ at $1150^{\circ} \mathrm{C}$, while the final residues had total concentrations of $96.1,88.4$, and $60.6 \mathrm{mg} / \mathrm{kg}$, respectively, with $\mathrm{Cd}$ undetected in both phases. The concentration levels fell within the regulatory threshold, indicating that the LWA fabricated from recycled metal sludge contains elements that are toxic and hazardous but not leached. Having no harmful effect on the environment, the metal sludge-based artificial LWA is not only safe but also practical with good physical properties.
\end{abstract}

(c) 2006 Elsevier B.V. All rights reserved.

Keywords: Artificial lightweight aggregate; Metal sludge; Sequential extraction method; ICP-AES; SEM/EDX

\section{Introduction}

Lightweight aggregate (LWA) is not only light and fire resistant, but also have good insulation against heat and sound. Its good engineering properties make it an ideal construction material [1-3]. The flourishing electronic industry in Taiwan has resulted in a huge accumulation of industrial waste, mainly metal sludge. Metal sludge produced in Taiwan in 2004 amounted to 580,000 tonnes [4]. The sludge contains various metals such as $\mathrm{Zn}, \mathrm{Cr}, \mathrm{Ni}, \mathrm{Cu}, \mathrm{Pb}$, and $\mathrm{Ag}$ originating from different industries involved in surface polishing, electroplating, as well as the production of printed circuit boards (PCB), batteries, electric wires, and cables. Studies have been done in recent years on the manufacturing of artificial LWA using recycled resources such as non-hazardous dredged silt and waste sludge. Research

\footnotetext{
* Corresponding author. Tel.: +886 22362 5373; fax: +88622392 8830 .

E-mail address: sllo@ccms.ntu.edu.tw (S.-L. Lo).
}

on metal sludge focuses mainly on its proper treatment without harmful effect on the environment, while little effort has been made on exploring the possibility and environmental impact of its recycling for resource recovery.

The most frequently used LWA is manufactured using bentonite, shale, perlite, vermiculite, expanded polystyrene, and different kinds of pelleted or sintered waste, including sintered glass. Under high-temperature heating, certain elements present in the raw materials expand, thus forming a hard vitrified layer on the surface [2]. Ramamurthy and Harikrishnan [5] observed that (i) properties of sintered aggregates vary with the type and amount of binder used and (ii) sintered aggregates show significant improvement in strength and reduction in water absorption when bentonite is added. Bhatty and Reidt [3] investigated the properties of lightweight sludge ash aggregate and reported that lightweight aggregate made from pelletized or slabbed sludge ash incinerated at between 1050 and $1110^{\circ} \mathrm{C}$ could produce concrete of moderate strength. Ducman et al. [6,7] explored the 
possibility of producing LWA in a rotary kiln at $1100^{\circ} \mathrm{C}$ using waste glass. Pioro and Pioro [8] employed non-selfbloating clays to produce aggregate for lightweight concrete with bulk density ranging between 160 and $850 \mathrm{~kg} / \mathrm{m}^{3}$ and cylindrical compressive strength within the range of $0.7-14.4 \mathrm{MPa}$. In addition, sewage sludge ash (SSA) [9-11] and clay-blended sludge [12] have also been recycled into LWA through sintering.

In this study, LWA is produced by sintering recycled mining residues and metal sludge from electronic industries in a tunnel kiln. The raw materials are fed at around $800{ }^{\circ} \mathrm{C}$ causing rapid vitrification of the raw aggregate pellet surface. The physical properties of the LWA thus obtained were examined by scanning electron microscopy (SEM) coupled with an energy dispersive $\mathrm{X}$-ray (EDX). The sequential extraction method combined with inductively coupled plasma atomic emission spectrometry (ICP-AES) was employed to determine the concentration and distribution of hazardous toxic elements in the non-sintered raw aggregate pellets and the sintered metal sludge-based LWA. This method has previously been used to measure the toxic metal content in fly ash [13]. Sequential extraction involves the addition of different reagents of increasing acidities in a series of steps to extract different elements, thus characterizing the chemical composition of the sample examined [14]. When used in the pre-treatment process, this method can provide information on the chemical composition distribution and the potential mobility of metal present in the waste to be recycled. Previous studies have mainly applied sequential extraction to analysis of toxic waste raw materials for recycling and rarely to that of recycled products, in this study the metal sludge-based LWA. Such analysis can contribute to a better understanding of whether the recycled LWA, which contains toxic elements, poses any harmful effect for the environment.

\section{Materials and method}

\subsection{Raw materials}

\subsubsection{Metal sludge}

Table 1 shows the analysis data of the total concentrations [15] and the TCLP leaching test [16] of the sludge cake obtained from electronic factories. As can be seen, copper $(\mathrm{Cu})$ constitutes

Table 1

Total concentrations and leaching concentrations of metal sludge

\begin{tabular}{llll}
\hline Element & $\begin{array}{l}\text { Total } \\
\text { concentrations } \\
(\mathrm{mg} / \mathrm{kg})\end{array}$ & $\begin{array}{l}\text { Leaching } \\
\text { concentrations } \\
(\mathrm{mg} / \mathrm{l})^{\mathrm{a}}\end{array}$ & $\begin{array}{l}\text { TCLP limits } \\
(\mathrm{mg} / \mathrm{l})[17]\end{array}$ \\
\hline Lead $(\mathrm{Pb})$ & $2452 \pm 22$ & $61.4 \pm 1.7$ & 5.0 \\
Cadmium $(\mathrm{Cd})$ & $275 \pm 15$ & $7.4 \pm 0.3$ & 1.0 \\
Copper $(\mathrm{Cu})$ & $3050 \pm 41$ & $96.0 \pm 2.5$ & 15.0 \\
Zinc $(\mathrm{Zn})$ & $118 \pm 9$ & $\mathrm{BDL}^{\mathrm{b}}$ & No limit \\
Total Chromium $(\mathrm{Cr})$ & $2492 \pm 39$ & $68.0 \pm 1.4$ & 5.0 \\
Chromium $\left(\mathrm{Cr}{ }^{+6}\right)$ & $34 \pm 2$ & $3.6 \pm 0.2$ & 2.5 \\
Arsenic $(\mathrm{As})$ & $\mathrm{BDL}$ & $\mathrm{BDL}$ & 5.0 \\
Mercury $(\mathrm{Hg})$ & $\mathrm{BDL}$ & $\mathrm{BDL}$ & 0.2 \\
\hline
\end{tabular}

${ }^{\text {a }}$ Extraction fluid \#1: $\mathrm{pH} 4.93 \pm 0.05$.

b BDL: below detection limit $(<0.002 \mathrm{mg} / \mathrm{l})$.
Table 2

Chemical composition of mining residues, metal sludge, and raw aggregate pellets before sintering

\begin{tabular}{lcrl}
\hline Composition & \multicolumn{1}{l}{$\begin{array}{l}\text { Mining } \\
\text { residues (\%) }\end{array}$} & $\begin{array}{l}\text { Metal } \\
\text { sludge (\%) }\end{array}$ & $\begin{array}{l}\text { Raw aggregate pellets } \\
\text { before sintering }(\%)\end{array}$ \\
\hline $\mathrm{SiO}_{2}$ & $56.3 \pm 2.5$ & $59.4 \pm 3.3$ & $58.3 \pm 2.8$ \\
$\mathrm{Al}_{2} \mathrm{O}_{3}$ & $14.4 \pm 0.9$ & $19.5 \pm 1.0$ & $17.1 \pm 0.9$ \\
$\mathrm{Fe}_{2} \mathrm{O}_{3}$ & $6.8 \pm 0.3$ & $6.0 \pm 0.4$ & $6.5 \pm 0.3$ \\
$\mathrm{CaO}$ & $5.1 \pm 0.2$ & $3.1 \pm 0.1$ & $4.3 \pm 0.2$ \\
$\mathrm{MgO}$ & $4.2 \pm 0.2$ & $1.5 \pm 0.1$ & $3.1 \pm 0.2$ \\
$\mathrm{Na}_{2} \mathrm{O}$ & $1.4 \pm 0.1$ & $2.9 \pm 0.1$ & $2.0 \pm 0.1$ \\
$\mathrm{~K}_{2} \mathrm{O}$ & $1.6 \pm 0.1$ & $2.0 \pm 0.1$ & $1.8 \pm 0.1$ \\
$\mathrm{P}_{2} \mathrm{O}_{5}$ & - & $1.1 \pm 0.1$ & $0.5 \pm 0.0$ \\
Others & $10.2 \pm 0.7$ & $4.5 \pm 0.2$ & $6.5 \pm 0.5$ \\
\hline
\end{tabular}

the highest proportion in the sludge $(3050 \mathrm{mg} / \mathrm{kg})$, followed by chromium $(\mathrm{Cr})$, lead $(\mathrm{Pb})$, cadmium $(\mathrm{Cd})$, and other hazardous metal wastes. The leaching concentration was much higher than the regulatory threshold [17]. The chemical composition of metal sludge is shown in Table 2.

\subsubsection{Mining residues}

Table 2 shows the composition of the residues (by XRF, as oxides) from a mine producing mainly shale, bentonite and kaolin. As can be seen, the residues comprise mainly silicon dioxide $\left(\mathrm{SiO}_{2}\right)$, followed by aluminum oxide $\left(\mathrm{Al}_{2} \mathrm{O}_{3}\right)$ and iron oxide $\left(\mathrm{Fe}_{2} \mathrm{O}_{3}\right)$, as well as the amounts of calcium oxide $(\mathrm{CaO})$, manganese oxide $(\mathrm{MgO})$, potassium oxide $\left(\mathrm{K}_{2} \mathrm{O}\right)$, and sodium oxide $\left(\mathrm{Na}_{2} \mathrm{O}\right)$. No hazardous metal was detected.

\subsection{Experimental procedure}

\subsubsection{LWA preparation}

The waste raw materials collected were oven dried at $105^{\circ} \mathrm{C}$ until constant weight was obtained. After sifting through the size of $75 \mu \mathrm{m}$, the metal sludge and mining residues were evenly mixed at a weight ratio of $40 \%: 60 \%$ into raw aggregate pellets of $3-5 \mathrm{~mm}$ diameter and then dried to contain $15 \%$ water [18]. Table 2 shows the chemical composition of the raw aggregate pellets before sintering. As seen in the compositional analysis, the pellets comprise mainly $\mathrm{SiO}_{2}$, followed by $\mathrm{Al}_{2} \mathrm{O}_{3}, \mathrm{Fe}_{2} \mathrm{O}_{3}$, and Flux, which matches the chemical composition of expandable LWA [19,20].

The raw aggregate pellets were then sintered at temperatures of $850,950,1050,1150$, and $1250{ }^{\circ} \mathrm{C}$ for $15 \mathrm{~min}$ [20] and cooled under ambient air. The sintered LWA thus obtained was then subjected to further examination as follows.

\subsubsection{Physical properties of sintered LWA}

The hydration rate was examined according to ASTM C12 [21], the apparent specific density was analyzed according to ASTM C127 [22] and the compressive strength was assessed using the method proposed by Yashima et al. [23].

\subsubsection{SEM/EDX investigation}

Morphological investigations of the LWA at different sintered temperatures were carried out by scanning electron microscopy 


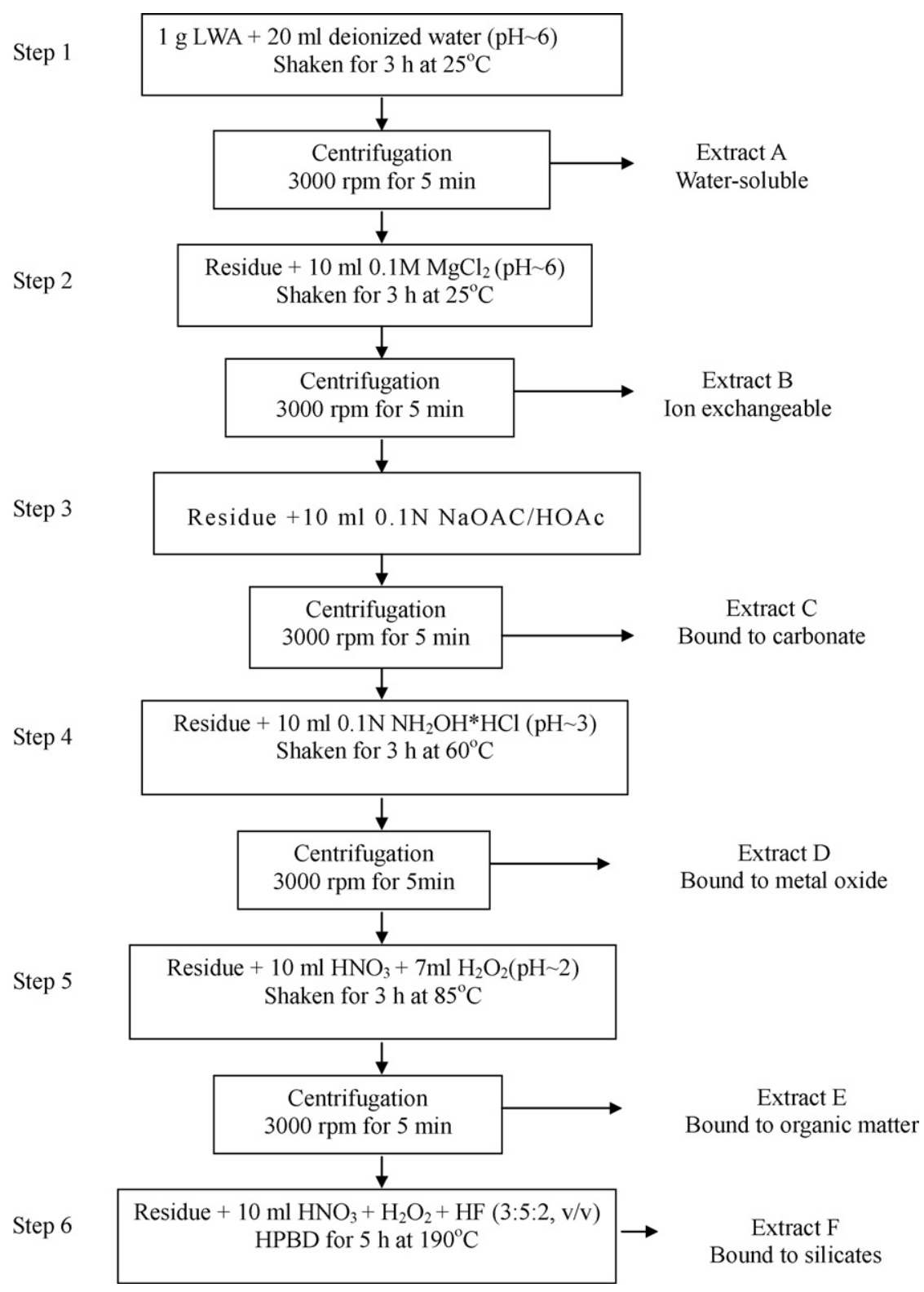

Fig. 1. Flowchart of sequential extraction procedure.

analyzer (SEM, JEOL JSM-6300F), coupled with an energy dispersive X-ray analyzer (EDX, Oxford Inca Energy 400). The typical accelerating voltage of SEM was $30 \mathrm{kV}$. The EDX detector used was a $\mathrm{Si}(\mathrm{Li})$ detector at a resolution of $133 \mathrm{eV}$.

\subsubsection{Sequential extraction procedure}

Following Chang et al. [13], we modified the original Tessier et al. [14] five-step sequential extraction scheme to examine the composition of toxic metal elements in the metal sludgebased LWA before sintering and after being sintered at different temperatures. Fig. 1 is the flowchart summarizing the sixstep sequential extraction method basically modified from the method proposed by Tessier et al. [14], but the residual fraction was particularly digested by $\mathrm{HNO}_{3} / \mathrm{H}_{2} \mathrm{O}_{2} / \mathrm{HF}$ acid mixture. Steps 1-5 were conducted in the same 15 -ml polyethylene centrifuge tube with the same extraction process by shaking at a speed of $150 \mathrm{rpm}$ for $3 \mathrm{~h}$ at different temperatures. The extract was then separated from the solid residue by centrifugation for $5 \mathrm{~min}$. The supernatant was removed with the pipette and stored in a polyethylene tube at $4{ }^{\circ} \mathrm{C}$ for analysis. Solid residue obtained after solid-liquid separation was to be used in the subsequent extraction process, thus, between each step, care had to be taken not to discard any such residue. In Step 6, after high-pressure bomb digestion, the sample solution was transferred into a PTFE beaker and heated gently $\left(<90^{\circ} \mathrm{C}\right)$ on a hot plate to allow the residual acid to evaporate. The final residue was diluted to $50 \mathrm{ml}$ for instrumental analysis.

The morphological and mineralogical phases after extraction were examined by SEM. The concentrations of major components (such as $\mathrm{Cd}, \mathrm{Cr}, \mathrm{Cu}$, and $\mathrm{Pb}$ ) in the different extracts were measured by inductively coupled plasma atomic emission spectrometry (ICP-AES). 
To evaluate the reproducibility of the results, all experiments were triplicated and the averaged results were presented.

\section{Results and discussion}

\subsection{Effect of sintering temperature on sludge-based LWA}

Fig. 2 shows the SEM surface images of sludge-based LWA sintered at different temperatures for $15 \mathrm{~min}$. As seen in Fig. 2(a), there are abundant pores present in the center, which are even and with thin boundary, while away from the center toward the vitrified surface, the pores becomes smaller and denser. Comparing the images in Fig. 2(b and c) reveals that higher sintering temperatures result in smaller and fewer pores on the LWA surface.

Fig. 3 shows pore formation inside the LWA sintered at different temperatures for $15 \mathrm{~min}$. As can be seen, the higher the temperature, the fewer and denser the pores formed inside the LWA.

The above results indicate that LWA sintered at higher temperature will be more densified and have lower porosity, which results in higher strength and lower hydration rate. Characteristics of LWA microstructure including particle size, shape and distribution of pores, extent of vitrification, and unit weight are all affected by sintering temperature $[11,20]$. For raw aggregate pellets fed at ambient temperature, their small size with diameter below $10 \mathrm{~mm}$ causes the temperature at the center to rise together with the kiln temperature. The pellet surface becomes rapidly vitrified under sintering and envelops the internal gas produced. As a result, pores are formed and the LWA thus obtained shows an expanded and porous structure.

\subsection{Toxic metal elements in sludge-based LWA}

Table 3 shows the concentration of toxic metal elements present in the sludge-based LWA before sintering and after being sintered at different temperatures. The results, expressed as a recovery $(\mathrm{mg} / \mathrm{kg})$ of the element determined in each step, correspond to the mean obtained in Steps 1-6 in the sequential extraction method. As can be seen, the metals extracted by Steps 1-6 include $\mathrm{Cd}, \mathrm{Cr}, \mathrm{Cu}$, and $\mathrm{Pb}$ with total concentrations of $108.4,990.3,1175.4$, and $976.0 \mathrm{mg} / \mathrm{kg}$, respectively, all of which exceed the standard specified by the US EPA [17] and are thus classified as hazardous wastes. After three steps of sequential extraction, the concentrations of $\mathrm{Cd}, \mathrm{Cr}, \mathrm{Cu}$, and $\mathrm{Pb}$ reached the levels of $3.8,146.0,88.8$, and $68.6 \mathrm{mg} / \mathrm{kg}$, which are close to the natural environmental leached levels. This is because metals in the water-soluble and ion exchangeable phases (Steps 1 and 2) are leachable under neutral conditions, while those bound to carbonates (Step 3) are leachable only under acidic conditions $(\mathrm{pH} \approx 5)$. Most metals bound to Fe-Mn oxides and organic matters (Step 4) are potentially leachable under reducing conditions; while those bound to silicates can hardly leach under natural conditions. It would thus be interesting to know whether toxic elements contained in the sludge-based LWA would be readily released into the environment or not. The real danger of sludgebased LWA is the amount of readily soluble constituents which is best represented by the first three extraction fractions in the experiment. Table 4 shows the sum of the first three extraction fractions for these elemental concentrations in the sludge-based LWA before sintering and after being sintered at different temperatures to indicate their availability in the environment. It was found that the extracted concentrations of $\mathrm{Cd}, \mathrm{Cu}$, and

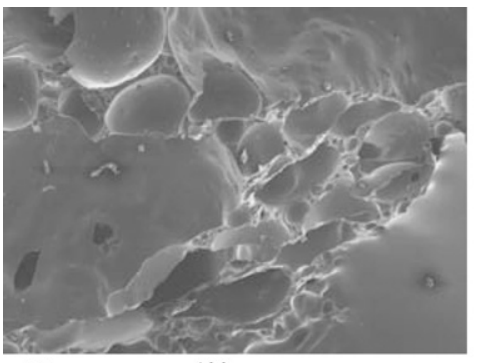

(a)

$100 \mu \mathrm{m}$

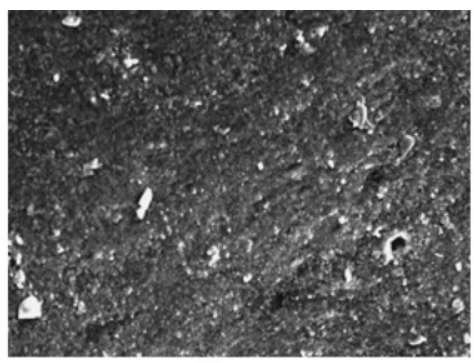

(b)
$50 \mu \mathrm{m}$

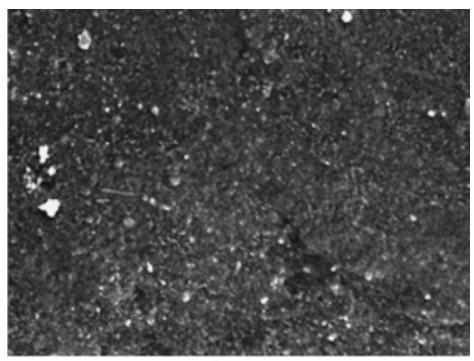

(c)
$50 \mu \mathrm{m}$

Fig. 2. SEM image of pores formed on surface of LWA sintered at different temperatures. (a) SEM image of LWA; (b) LWA sintered at $1050{ }^{\circ} \mathrm{C}$; (c) LWA sintered at $1250^{\circ} \mathrm{C}$.

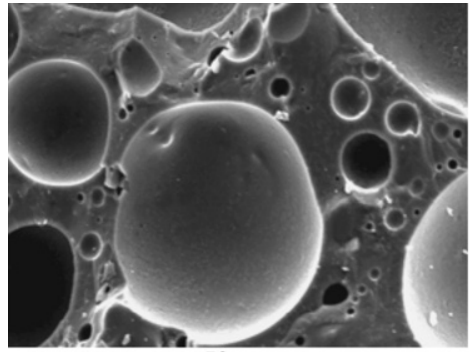

(a)

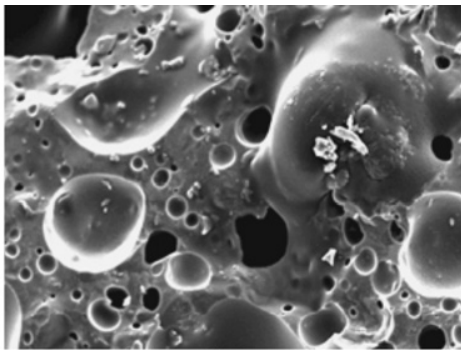

(b)

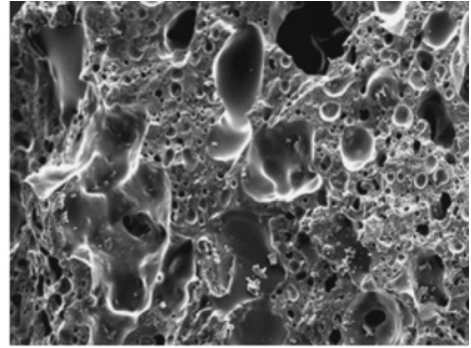

(c)
$100 \mu \mathrm{m}$

Fig. 3. SEM image of pores formed inside LWA sintered at different temperatures. (a) LWA sintered at $1050{ }^{\circ} \mathrm{C}$; (b) LWA sintered at $1150^{\circ} \mathrm{C}$; (c) LWA sintered at $1250^{\circ} \mathrm{C}$. 
Table 3

Concentration of toxic elements in metal sludge-based LWA before and after sintering at different temperatures (unit: $\mathrm{mg} / \mathrm{kg}$ )

\begin{tabular}{|c|c|c|c|c|c|c|}
\hline Sample & Non-sintered & $850^{\circ} \mathrm{C}$ & $950^{\circ} \mathrm{C}$ & $1050^{\circ} \mathrm{C}$ & $1150^{\circ} \mathrm{C}$ & $1250^{\circ} \mathrm{C}$ \\
\hline \multicolumn{7}{|l|}{ Extract A } \\
\hline $\mathrm{Cd}$ & $\mathrm{BDL}^{\mathrm{a}}$ & BDL & BDL & BDL & BDL & BDL \\
\hline $\mathrm{Cr}$ & $5.4 \pm 0.6$ & $75.6 \pm 5.8$ & $89.6 \pm 7.4$ & $81.6 \pm 9.1$ & $29.8 \pm 1.5$ & $2.0 \pm 0.1$ \\
\hline $\mathrm{Cu}$ & $4.6 \pm 0.4$ & $5.4 \pm 0.5$ & $5.6 \pm 0.6$ & $5.8 \pm 0.4$ & $7.0 \pm 0.4$ & $11.2 \pm 0.8$ \\
\hline $\mathrm{Pb}$ & BDL & $4.0 \pm 0.2$ & $7.0 \pm 0.8$ & $18.0 \pm 0.7$ & $10.0 \pm 0.7$ & $11.6 \pm 1.2$ \\
\hline \multicolumn{7}{|l|}{ Extract B } \\
\hline $\mathrm{Cd}$ & BDL & BDL & BDL & BDL & BDL & BDL \\
\hline $\mathrm{Cr}$ & $3.0 \pm 0.2$ & $89.0 \pm 10.1$ & $103.4 \pm 9.2$ & $21.4 \pm 1.3$ & $19.4 \pm 1.0$ & $1.6 \pm 0.1$ \\
\hline $\mathrm{Cu}$ & $8.0 \pm 0.8$ & $9.6 \pm 0.6$ & $7.0 \pm 0.6$ & $2.4 \pm 0.5$ & $7.0 \pm 0.6$ & $11.2 \pm 1.0$ \\
\hline $\mathrm{Pb}$ & $34.2 \pm 3.6$ & $10.0 \pm 0.9$ & $11.0 \pm 1.1$ & $12.0 \pm 0.9$ & $14.0 \pm 0.7$ & $12.6 \pm 0.9$ \\
\hline \multicolumn{7}{|l|}{ Extract C } \\
\hline $\mathrm{Cd}$ & $3.8 \pm 0.1$ & BDL & BDL & BDL & BDL & BDL \\
\hline $\mathrm{Cr}$ & $137.6 \pm 8.4$ & $58.0 \pm 3.4$ & $25.0 \pm 1.3$ & $9.0 \pm 0.6$ & $4.6 \pm 0.2$ & $1.6 \pm 0.1$ \\
\hline $\mathrm{Cu}$ & $76.2 \pm 6.2$ & $88.6 \pm 6.1$ & $17.0 \pm 0.9$ & $16.2 \pm 1.2$ & $16.0 \pm 0.8$ & $10.0 \pm 0.8$ \\
\hline $\mathrm{Pb}$ & $34.2 \pm 4.2$ & $10.0 \pm 1.0$ & $9.0 \pm 0.5$ & $22.0 \pm 1.8$ & $13.6 \pm 0.6$ & $0.6 \pm 0.0$ \\
\hline \multicolumn{7}{|l|}{ Extract D } \\
\hline $\mathrm{Cd}$ & $19.0 \pm 1.0$ & $\mathrm{BDL}$ & $\mathrm{BDL}$ & BDL & BDL & BDL \\
\hline $\mathrm{Cr}$ & $168.4 \pm 9.2$ & $30.2 \pm 2.3$ & $19.0 \pm 1.0$ & $8.4 \pm 0.5$ & $7.0 \pm 0.3$ & $3.4 \pm 0.2$ \\
\hline $\mathrm{Cu}$ & $168.8 \pm 11.4$ & $141.2 \pm 9.9$ & $20.0 \pm 1.4$ & $16.2 \pm 1.4$ & $7.2 \pm 0.3$ & $10.6 \pm 0.9$ \\
\hline $\mathrm{Pb}$ & $222.8 \pm 18.2$ & $16.0 \pm 1.2$ & $17.0 \pm 0.7$ & $18.0 \pm 1.0$ & $11.2 \pm 0.9$ & $0.6 \pm 0.0$ \\
\hline \multicolumn{7}{|c|}{ Extract E } \\
\hline $\mathrm{Cd}$ & $83.8 \pm 3.6$ & BDL & $\mathrm{BDL}$ & $\mathrm{BDL}$ & BDL & BDL \\
\hline $\mathrm{Cr}$ & $396.2 \pm 28.6$ & $95.2 \pm 6.5$ & $75.2 \pm 8.6$ & $50.6 \pm 2.5$ & $11.0 \pm 0.5$ & $5.6 \pm 0.3$ \\
\hline $\mathrm{Cu}$ & $624.8 \pm 53.0$ & $110.0 \pm 9.6$ & $30.4 \pm 1.5$ & $22.8 \pm 1.7$ & $15.8 \pm 1.1$ & $11.8 \pm 1.3$ \\
\hline $\mathrm{Pb}$ & $249.6 \pm 34.4$ & $18.0 \pm 1.9$ & $12.0 \pm 1.0$ & $4.0 \pm 0.2$ & $12.0 \pm 0.6$ & $15.6 \pm 1.5$ \\
\hline \multicolumn{7}{|l|}{ Extract $\mathrm{F}$} \\
\hline $\mathrm{Cd}$ & $1.6 \pm 0.1$ & $9.6 \pm 0.7$ & $4.6 \pm 0.3$ & BDL & BDL & BDL \\
\hline $\mathrm{Cr}$ & $279.8 \pm 25.8$ & $150.8 \pm 14.6$ & $111.8 \pm 10.4$ & $82.6 \pm 6.3$ & $24.4 \pm 1.5$ & $1.6 \pm 0.1$ \\
\hline $\mathrm{Cu}$ & $293.0 \pm 31.8$ & $241.6 \pm 12.9$ & $83.8 \pm 7.2$ & $64.8 \pm 4.9$ & $35.8 \pm 2.0$ & $21.0 \pm 1.4$ \\
\hline $\mathrm{Pb}$ & $435.0 \pm 48.8$ & $113.2 \pm 7.3$ & $61.8 \pm 5.5$ & $9.8 \pm 0.7$ & $0.2 \pm 0.0$ & BDL \\
\hline
\end{tabular}

a BDL: below detection limit $(<0.002 \mathrm{mg} / \mathrm{l})$.

$\mathrm{Pb}$ in the sludge-based LWA after being sintered at different temperatures through the first three steps are much lower than their regulated TCLP limits. However, the $\mathrm{Cr}$ concentrations for sintering temperatures between 850 and $1050^{\circ} \mathrm{C}$ exceed the regulated TCLP limits, with a much weaker set of reagents. This is because the $\mathrm{Cr}$ compounds were converted into more soluble or more extractable forms after sintering. Hazardous metals will be encapsulated in the silicate matrix structure when sintered at high temperature $\left(>1150^{\circ} \mathrm{C}\right)$, making them non-volatile vitrified residues with low leachability. Hence, high-temperature sintering can be an effective treatment approach for volatile metals. Moreover, the longer the sintering and the higher temperature, the lower the leachability of hazardous metals.
Table 5 shows the recovery of metals in each sequential extraction step for non-sintered LWA pellets. As can be seen, $77.3 \%, 40.0 \%, 53.2 \%$, and $25.6 \%$ of $\mathrm{Cd}, \mathrm{Cr}, \mathrm{Cu}$, and $\mathrm{Pb}$, respectively, were bound to organic matter, while $28.3 \%, 24.9 \%$, and $44.6 \%$ of $\mathrm{Cr}, \mathrm{Cu}$, and $\mathrm{Pb}$, respectively, were bound to silicates. In addition, $3.5 \%, 14.7 \%, 7.6 \%$, and $7.0 \%$ of $\mathrm{Cd}, \mathrm{Cr}, \mathrm{Cu}$, and $\mathrm{Pb}$, respectively, were dissolved after Steps 1-3. In the presence of microorganisms, metals bound to organic matter might be decomposed and become a potential pollutant, implying that small amounts of $\mathrm{Cd}, \mathrm{Cr}, \mathrm{Cu}$, and $\mathrm{Pb}$ are leached in the natural environment. Since these four elements are all toxic, their release during storage will have a potentially negative impact on environmental quality, human health, as well as surface-

Table 4

Comparisons between the sums of first three extraction fractions for toxic elements in metal sludge-based LWA and the TCLP limits (unit: $\mathrm{mg} / \mathrm{l}$ )

\begin{tabular}{llllllll}
\hline Sample & Non-sintered & $850^{\circ} \mathrm{C}$ & $950{ }^{\circ} \mathrm{C}$ & $1050^{\circ} \mathrm{C}$ & $1150^{\circ} \mathrm{C}$ & $1250^{\circ} \mathrm{C}$ \\
\hline $\mathrm{Cd}$ & $0.19 \pm 0.01$ & $\mathrm{BDL}^{\mathrm{a}}$ & $\mathrm{BDL}$ & $\mathrm{BDL}$ & $\mathrm{BDL}$ & $\mathrm{BDL}$ & 1.0 \\
$\mathrm{Cr}$ & $7.30 \pm 0.46$ & $11.12 \pm 0.97$ & $10.91 \pm 0.90$ & $5.60 \pm 0.55$ & $2.69 \pm 0.14$ & $0.25 \pm 0.02$ & 5.0 \\
$\mathrm{Cu}$ & $4.44 \pm 0.37$ & $5.17 \pm 0.36$ & $1.47 \pm 0.09$ & $1.22 \pm 0.11$ & $1.50 \pm 0.09$ & $1.63 \pm 0.13$ & 15.0 \\
$\mathrm{~Pb}$ & $3.43 \pm 0.39$ & $1.19 \pm 0.11$ & $1.34 \pm 0.12$ & $2.59 \pm 0.17$ & $1.88 \pm 0.10$ & $1.25 \pm 0.11$ & 5.0 \\
\hline
\end{tabular}

a BDL: below detection limit $(<0.002 \mathrm{mg} / \mathrm{l})$. 
Table 5

Recovery (\%) of metals in each sequential extraction step for non-sintered LWA pellets $(n=3)$

\begin{tabular}{|c|c|c|c|c|c|c|}
\hline \multirow[t]{2}{*}{ Element } & \multicolumn{6}{|c|}{ Recovery (\%) } \\
\hline & $\mathrm{A}^{\mathrm{a}}$ & $\mathrm{B}$ & $\mathrm{C}$ & $\mathrm{D}$ & $\mathrm{E}$ & $\mathrm{F}$ \\
\hline $\mathrm{Cd}$ & - & - & $3.5(0.1)$ & $17.5(0.9)$ & $77.3(3.3)$ & $1.6(0.1)$ \\
\hline $\mathrm{Cu}$ & $0.4(0.0)$ & $0.7(0.1)$ & $6.5(0.5)$ & $14.4(1.0)$ & $53.2(4.5)$ & $24.9(2.7)$ \\
\hline $\mathrm{Pb}$ & - & $3.5(0.4)$ & $3.5(0.4)$ & $22.8(1.9)$ & $25.6(3.5)$ & $44.6(5.0)$ \\
\hline
\end{tabular}

a Extracts: (A) water-soluble, (B) ion-exchangeable, (C) bound to carbonates, (D) bound to Fe-Mn oxides, (E) bound to organic matter and (F) silicates

b Values presented in parentheses are the relative standard deviations.

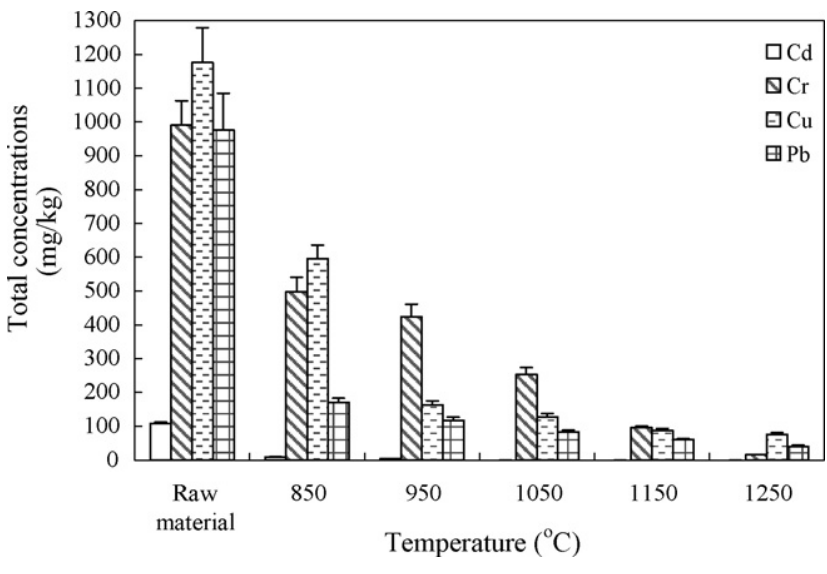

Fig. 4. Total metal concentrations at different sintering temperatures.

and ground-water resources; pretreatment is thus needed before utilization.

Fig. 4 shows the total metal concentration at different sintering temperatures. As can be seen, the concentration of $\mathrm{Cd}, \mathrm{Cr}$, $\mathrm{Cu}$, and $\mathrm{Pb}$ in raw LWA pellets amount to $108.4,990.3,1175.4$, and $976.0 \mathrm{mg} / \mathrm{kg}$, respectively. With increasing sintering temperatures, the amounts of metals leached decreased, resulting in a falling trend in the total concentrations. At sintering temperature of $1150^{\circ} \mathrm{C}$, the concentrations of $\mathrm{Cr}, \mathrm{Cu}$, and $\mathrm{Pb}$ leached dropped to $96.2,88.4$, and $60.6 \mathrm{mg} / \mathrm{kg}$, respectively, with $\mathrm{Cd}$ undetected. Concentrations of metals leached from LWA sintered at this temperature were much lower than the regulatory threshold [17]. Sintering at higher temperature of $1250^{\circ} \mathrm{C}$ further reduced the concentrations of $\mathrm{Cr}, \mathrm{Cu}$, and $\mathrm{Pb}$ to $15.8,75.8$, and $41.0 \mathrm{mg} / \mathrm{kg}$, respectively.

\subsection{Morphology analysis with SEM/EDX}

Fig. 5 shows the SEM and EDX images of the non-sintered raw aggregate pellets for manufacturing LWA. A fragmented structure can be seen in the SEM image while elemental analysis performed by EDX revealed that the pellets contained $\mathrm{Si}, \mathrm{O}, \mathrm{Al}$, $\mathrm{Ca}$, and $\mathrm{Fe}$. Hence, the crystals formed were compounds of $\mathrm{SiO}_{2}$ and $\mathrm{Al}_{2} \mathrm{O}_{3}$. Owing to the agglomeration of the particles, accurate quantitative measurement could not be made by surface analysis.

Step 3 of the sequential extraction method uses $\mathrm{NaOAc} /$ $\mathrm{HOAc}(\mathrm{pH} \sim 5)$ as reagent, simulating leaching under acid rain. Fig. 6 shows the SEM/EDX image of NaOAc/HOAc-leached LWA. As can be seen, the shape of the sphere surface had turned irregular, indicating that some of the matters on the sphere surface had been extracted in this step. Elemental analysis performed by EDX revealed that the residue contained $\mathrm{SiO}_{2}$ with $\mathrm{Al}, \mathrm{Ca}, \mathrm{K}, \mathrm{Cd}$, and $\mathrm{S}$ being leached in the process. This implies that only weak physical bonds are formed between these elements and the compounds on the residue surface, and thus they are leached easily, posing a detrimental impact on the environment.

Further extraction using reagents $\mathrm{NH}_{2} \mathrm{OH}^{\bullet} \mathrm{HCl}$ (Step 4) and $\mathrm{HNO}_{3}+\mathrm{H}_{2} \mathrm{O}_{2}$ (Step 5) simulated the leaching of toxic metals under reducing and oxidizing conditions. Fig. 7 depicts the SEM/EDX image of LWA at the final step of extraction using $\mathrm{HNO}_{3}+\mathrm{H}_{2} \mathrm{O}_{2}+\mathrm{HF}$. As can be seen, under strong reducing condition, some of the oxidized metals were extracted and small particles were formed. The broken sphere was filled with many smaller spheres composed of $\mathrm{Al}, \mathrm{Mg}$, and $\mathrm{Si}$ oxides as seen in the EDX image. Elemental analysis performed by EDX revealed that the residue contained mainly $\mathrm{SiO}_{2}$ and other metal oxides with $\mathrm{Fe}, \mathrm{Mn}, \mathrm{As}, \mathrm{Pb}, \mathrm{Cu}$, and $\mathrm{Zn}$ being leached in the

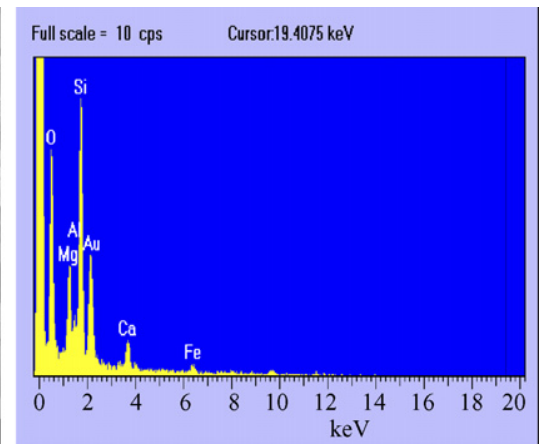

Fig. 5. SEM/EDX analysis of non-sintered raw aggregate pellets. 

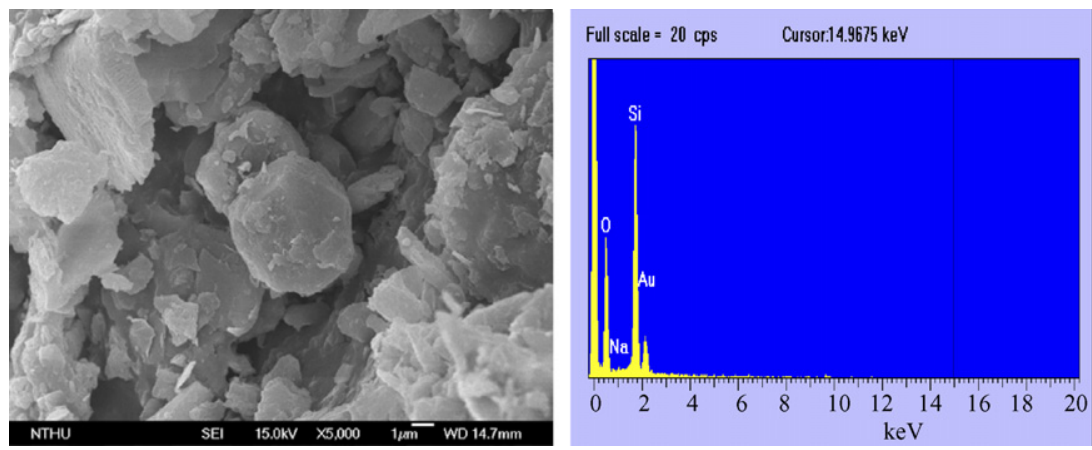

Fig. 6. SEM/EDX analysis of NaOAc/HO Ac-leached LWA.
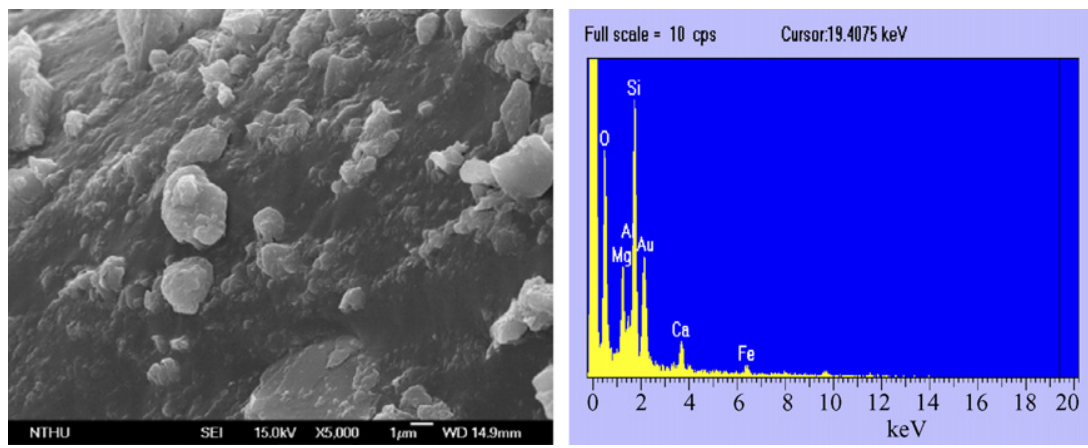

Fig. 7. SEM/EDX analysis of $\mathrm{HNO}_{3}+\mathrm{H}_{2} \mathrm{O}_{2}+$ HF-leached LWA.

process. This implies that stronger chemical bonds are formed between these elements and the compounds on the residue surface, making it difficult for them to be leached even under acid rain condition. In other words, the toxic metals present in the LWA cannot be easily leached and pose no harmful impact on the environment.

\subsection{Physical properties of metal sludge-based LWA}

Table 6 lists the physical properties of metal sludge-based LWA sintered at different temperatures. As can be seen, the higher the sintering temperature, the lower the hydration rate. Beyond $1050{ }^{\circ} \mathrm{C}$, the hydration rate drops below $5 \%$. It can be attributed to more complete vitrification of the LWA surface at higher sintering temperature. As mentioned above, LWA has a porous structure; thus, the hydration rate is directly related with the number of open pores on the surface. On the other hand, the porosity also affects the compressive strength of the LWA. Higher compressive strength can be obtained using more densified aggregates with spherical shape, good surface polish, higher

Table 6

Physical properties of metal sludge-based LWA

\begin{tabular}{llll}
\hline $\begin{array}{l}\text { Sintering } \\
\text { temperature }\left({ }^{\circ} \mathrm{C}\right)\end{array}$ & \multicolumn{1}{l}{$\begin{array}{l}\text { Hydration } \\
\text { rate }(\%)\end{array}$} & $\begin{array}{l}\text { Apparent specific } \\
\text { density }\left(\mathrm{g} / \mathrm{cm}^{3}\right)\end{array}$ & $\begin{array}{l}\text { Compressive } \\
\text { strength }(\mathrm{MPa})\end{array}$ \\
\hline 850 & $22.15 \pm 2.11$ & $1.11 \pm 0.06$ & $3.33 \pm 0.25$ \\
950 & $12.03 \pm 0.87$ & $1.07 \pm 0.03$ & $5.49 \pm 0.18$ \\
1050 & $7.56 \pm 0.46$ & $0.89 \pm 0.02$ & $7.55 \pm 0.31$ \\
1150 & $4.51 \pm 0.33$ & $0.74 \pm 0.02$ & $4.41 \pm 0.26$ \\
1250 & $4.20 \pm 0.19$ & $1.18 \pm 0.07$ & $8.04 \pm 0.35$ \\
\hline
\end{tabular}

density, low hydration rate, and small pores. In this study, the main concern is to achieve better expansion and low weight and density of obtained LWA. As seen in Table 6, the lowest density of $0.74 \mathrm{~g} / \mathrm{cm}^{3}$ can be obtained at sintering temperature of $1150^{\circ} \mathrm{C}$. Below $1150{ }^{\circ} \mathrm{C}$, the sintering temperature is too low to achieve complete vitrification of the raw pellet surface. On the other hand, sintering beyond this temperature will melt all crystals, thus reducing the pore ratio, which in turn increases the density to $1.18 \mathrm{~g} / \mathrm{cm}^{3}$. Compressive strength was found to increase with increasing sintering temperature and reached its first peak of $7.55 \mathrm{MPa}$ at $1050{ }^{\circ} \mathrm{C}$. The reduction in compressive strength at $1150^{\circ} \mathrm{C}$ can be attributed to the lower density as a result of an increase in porosity. Finally, with increasing density at $1250{ }^{\circ} \mathrm{C}$, the compressive strength rises again to its highest degree of $8.04 \mathrm{MPa}$.

\section{Conclusion}

Great care should be taken when using recycled resources to manufacture LWA because of the different leachability of toxic elements present in the waste materials. Knowledge of the chemicals and physical properties of metal sludge-based artificial lightweight aggregate is needed to assess the risk of potential environmental mobility of the trace toxic metals.

The findings of this study reveal that sintering of metal sludge-based artificial lightweight aggregate in a tunnel kiln can promote rapid vitrification of the raw pellet surface, thus facilitating the expansion of the LWA, which is best achieved at $1150{ }^{\circ} \mathrm{C}$. The concentrations of metals leached tend to decrease with increasing sintering temperature. Results obtained by 
sequential extraction show that concentrations of $\mathrm{Cd}, \mathrm{Cr}, \mathrm{Cu}$, and $\mathrm{Pb}$ in LWA sintered at $1150^{\circ} \mathrm{C}$ for 15 min dropped significantly to the regulatory threshold. This gives evidence that metal sludge-based LWA not only possesses good physical properties, but also poses no harmful effect on the environment.

\section{References}

[1] A. Kilic, C.D. Atis, E. Yasar, F. Ozcan, High-strength lightweight concrete made with scoria aggregate containing mineral admixtures, Cem. Concr. Res. 33 (10) (2003) 1595-1599.

[2] A. Short, W. Kinniburgh, Lightweight Concrete. Building Research Establishment, Garston Watford, UK, 1976.

[3] J.I. Bhatty, K.J. Reidt, Moderate strength concrete from lightweight sludge ash aggregate, Cem. Compos. Lightweight Concr. 11 (3) (1989) 179-187.

[4] Yearbook of Environmental Protection Statistics Republic of China, Environmental Protection Administration, ROC, 2005.

[5] K. Ramamurthy, K.I. Harikrishnan, Influence of binders on properties of sintered fly ash aggregate, Cem. Concr. Compos. 28 (1) (2006) 33-38.

[6] V. Ducman, A. Mladenovic, J.S. Suput, Lightweight aggregate based on waste glass and its alkali-silica reactivity, Cem. Concr. Res. 32 (2) (2002) 223-226.

[7] V. Ducman, M. Kovacevic, High porosity granules produced from waste glass, Kovine, Zlitine, Technology 33 (5) (1999) 377-379.

[8] L.S. Pioro, I.L. Pioro, Production of expanded-clay aggregate for lightweight concrete from non-selfbloating clays, Cem. Concr. Compos. 26 (6) (2004) 639-643.

[9] J.H. Tay, W.K. Yip, Sludge ash as lightweight concrete material, J. Environ. Eng. 115 (1) (1989) 56-64.

[10] C.R. Cheeseman, G.S. Virdi, Properties and microstructure of lightweight aggregate produced from sintered sewage sludge ash, Resour. Conserv. Recycl. 45 (2005) 18-30.
[11] K.S. Wang, C.J. Tseng, I.J. Chiou, M.H. Shih, The thermal conductivity mechanism of sewage sludge ash lightweight materials, Cem. Concr. Res. 35 (4) (2005) 803-809.

[12] J.H. Tay, W.K. Yip, K.Y. Show, Clay-blended sludge as lightweight aggregate concrete material, J. Environ. Eng. 117 (6) (1991) 834-844.

[13] C.Y. Chang, H.L. Chiang, Z.J. Su, C.F. Wang, A sequential extraction method measures the toxic metal content in fly ash from a municipal solid waste incinerator, J. Chin. Chem. Soc. 52 (2005) 921-926.

[14] A. Tessier, P.G.C. Campbell, M. Bisson, Sequential extraction procedure for the speciation of particulate trace metals, Anal. Chem. 51 (1979) 844-851.

[15] Acid Digestion of Sediments, Sludges, and Soils, SW 846-3050b, US EPA, 1996.

[16] Toxicity Characteristic Leaching Procedure, SW 846-1311, US EPA, 1992.

[17] Characteristics Introduction and Regulatory Definitions, Test Methods for Evaluating Solid Waste, Physical/Chemical Methods (SW 846), US Environmental Protection Agency, 2004.

[18] S.C. Huang, F.C. Chang, S.L. Lo, M.Y. Lee, C.F. Wang, J.D. Lin, Production of lightweight aggregates from mining residues, heavy metal sludge, and incinerator fly ash, J. Hazard. Mater. 144 (2007) 52-58.

[19] C.M. Riley, Relation of chemical properties to the bloating clay, J. Am. Ceram. Soc. 34 (4) (1951) 121-128.

[20] C.C. Tsai, K.S. Wang, I.J. Chiou, Effect of $\mathrm{SiO}_{2}-\mathrm{Al}_{2} \mathrm{O}_{3}$-flux ratio change on the bloating characteristics of lightweight aggregate material produced from recycled sewage sludge, J. Hazard. Mater. 134 (2006) 87-93.

[21] Standard Practice for Installing Vitrified Clay Pipe Lines, ASTM C12-06, ASTM International, 2005.

[22] Standard Test Method for Density, Relative Density (Specific Gravity), and Absorption of Coarse Aggregate, ASTM C127-04, ASTM International, 2006.

[23] S. Yashima, Y. Kanda, S. Sano, Relationship between particle size and fracture energy or impact velocity required to fracture as estimated from single particle crushing, Powder Technol. 51 (3) (1987) 277-282. 